İş ve İnsan Dergisi | The Journal of Human and Work

Y1l | Year: Nisan | April 2020

Cilt-Say1 | Volume-Issue: 7 (1)

ss I pp: $137-146$

doi: $10.18394 /$ iid.596167

e-ISSN 2148-967X

https://dergipark.org.tr/tr/pub/iid

Araştırma Makalesi

\title{
Tersine Mentorluk Üzerine Bir Değerlendirme: The Intern (Stajyer) Filmi Örneği *
}

\author{
An Evaluation of Reverse Mentoring: The Intern Movie Case
}

\author{
Samet Özdemir ${ }^{a}$, Kadir Ardıç
}

\section{MAKALE BİLGİSI}

Anahtar Kelimeler:

Tersine Mentorluk

Mentorluk, Popüler Kültür,

Sinema, Stajyer

Tarihler :

Geliș 24 Temmuz 2019

Düzeltme geliş 19 Kasım

2019

Kabul 10 Aralık 2019

\begin{abstract}
ÖZ
Pek çok yönetim uygulaması gibi mentorluk da kendisini değişsen şartlara göre yeniden düzenlemektedir. Tersine mentorluk, bilişim teknolojilerinin gelişmesi, çallş̧ma koşullarının farklılaşması, iş hayatına giren yeni kuşakların önceki kuşaklardan farklı beklentilere sahip olması gibi sebeplerle yeni bir mentorluk anlayışı olarak ortaya çıkmıştır. Bu çalışmada tersine mentorluğa ilişkin izler taşıdığı düşünülen ve 2015 yllında gösterime girmiş olan The Intern (Stajyer) filmi incelenmiştir. Filmin başrolleri arasindaki ilişki tersine mentorluk işlev ve alt işlevleri bağlamında ele alınmış̧ır. Nitel araştırma yöntemleri benimsenerek yürütülen çalışmada analiz tekniği olarak betimsel analiz tercih edilmiștir. Yapılan analiz ile birlikte; bilgi paylaşımı, açı̆̆a çıkarma ve görünürlük, meydan okuma ve zorluklar, sosyal ağlar, kabul ve onaylama, arkadaşlık, cesaretlendirme ve rol model alt işlevlerinin filmde işlendiği sonucuna ulaşılmıştır. Koçluk, yetenek gelişimi ile destek ve geribildirim alt işlevlerinin ise filmde yer almadı̆̆ görülmü̈şür.
\end{abstract}

\section{ARTICLE INFO}

\section{Keywords:}

Reverse Mentoring,

Mentoring, Popular Culture,

Movie, Intern

Article history:

Received 24 July 2019

Received in revised 19

November 2019

Accepted 10 December 2019

\begin{abstract}
A B S T R A C T
Like many management practices, mentoring reorganizes itself according to changing circumstances. Reverse mentoring has emerged as a new mentoring mentality due to the development of information technologies, differentiation of working conditions and the fact that new generations entering the business life have different expectations from previous generations. The Intern (The Intern) as a movie which was thought to have traces of reverse mentoring and was released in 2015, was examined in the study. The relationship between the starring characters of the film is discussed in the context of reverse mentoring functions and sub-functions. Qualitative research methods were adopted and descriptive analysis was used as the analysis technique. With the analysis functions of knowledge sharing, exposure and visibility, challenging ideas, social networks, acceptance and confirmation, friendship, affirmation and encouragement and role model have been concluded in the film. Coaching, support and feedback with skill development functions were not included in the film.
\end{abstract}

\footnotetext{
* Bu makale 18-27 Eylül 2017 tarihlerinde Íspanya'da düzenlenen 1. Uluslararası Sosyal Bilimler Kongresi’nde sunulan özet bildirinin genişletilmiş ve yeniden düzenlenmiş halidir.

a İletişim kurulacak yazar, Araş. Gör., Sakarya Üniversitesi, İşletme Fakültesi, Insan Kaynakları Yönetimi, Sakarya, Türkiye. E-mail: sametozdemir@sakarya.edu.tr.ORCID:0000-0003-4753-7772

${ }^{\mathrm{b}}$ Prof. Dr., Kırgızistan Türkiye Manas Üniversitesi, İktisadi ve İdari Bilimler Fakültesi, İsletme Bölümü, Biskek, Kırgızistan. E-mail: kadir.ardich@manas.edu.kg.ORCID:0000-0001-7851-9564
} 


\section{GİRIŞ}

Mentorluk günümüzde araştırmalara sık sık konu edilen popüler bir konudur. Ancak günümüzde elde etmiş olduğu popülariteye rağmen yeni bir kavram olmadığı, köklerinin 3500 yıl öncesine kadar uzandığı bilinmektedir. Yunanlı ozan Homeros, Odyssey Destanı'nda mentor kelimesini kullanmıştır (Stone, 2002). Destanlara konu olduğu günden bu yana mentorluk kavramı, çok çeşitli coğrafi bölgeler, kültürler ve disiplinler tarafından farklı şekillerde yorumlanmış ve kullanılmıştır. $\mathrm{Bu}$ nedenle mentorluğun tek bir ifade ediliş biçimi olmamakla birlikte 50'den fazla tanımı olduğu bilinmektedir (Crisp \& Cruz, 2009). Genel bir tanım ile mentorluk, iki taraf arasında bireysel ve profesyonel gelişime destek olmak amacıyla uzmanlık, deneyim ve düşüncelerin paylaşıldığı bir anlaşmadır (Çınar, 2010: 16). Hem bir kariyer yönetimi aracı hem de bir eğitim geliştirme uygulaması olarak düşünüldüğünde; mentorluk, çok daha önemli ve yaygın bir uygulama olarak karşımıza çıkmaktadır.

\section{MENTORLUK ve TERSINE MENTORLUK}

Mentorluk, biri tecrübeli, biri tecrübesiz iki kişi arasında, "karşılıklılık" prensibine dayanan "gönüllü, derin, adanmış, geniș kapsamlı, dinamik, destekleyici, güvene dayalı" bir ilişkidir (Hayes, 2005: 442-445). Mentorluk, eğitim ile gerçek hayat tecrübesi arasında köprü vazifesi gören bir süreçtir (Barker, 2006: 56). Sözü edilen süreç biri tecrübeli diğeri tecrübesiz iki çalışan arasında geçen bir ilişki anlamına gelmektedir. İlişkinin daha tecrübeli olan ve öğretici konumundaki tarafına mentor, daha tecrübesiz ve öğrenci konumundaki tarafina ise menti denmektedir (Kram, 1985). Hem bir süreç hem de karşılıklı bir ilişki olması mentorluk tanımlarında çok kez tekrar edilen önemli noktalar olmuştur.

Geçmişten günümüze, mentorluk yeni türleriyle uygulamaya geçmiş, çeşitli teknikleri bünyesine katarak uygulanabilirliğini korumuştur. Tersine mentorluk, bahsedilen bu yeni uygulamalardan biri olarak ortaya çıkmıştır. Tersine mentorluk, mentinin mentordan daha yüksek bir hiyerarşik düzeyde olduğu yeni nesil bir mentorluk türünü ifade eder (Murphy, 2012). Teknolojinin hızla gelişmesi ve iş hayatında birçok yeniliğe sebep olması, bilişim ve telekomünikasyon gibi alanlarda yetişmiş genç çalışanları ortaya çıkarmıştır. Yaşları daha küçük olmalarına rağmen bu genç çalışanlar kendi alanlarında daha tecrübeli olabilirler ve mentorluk yapabilirler (Busen \& Engebretson, 1999). Tersine mentorluk, geleneksel mentorluğun tam aksi yönünde formüle edilmiş şeklini ve aynı zamanda mentor ve menti rollerinin değiştiği bir ilişki türünü ifade etmektedir.

İş hayatında kıdemli bir çalışanla kıdemsiz genç bir çalışan arasında hızla değişen teknolojinin kavranabilmesi için düzenlenen formal ve/veya informal iş ilişkisine tersine mentorluk denmektedir (Hays \& Swanson, 2011: 1). Tersine mentorluğun başarılı bir uygulaması olarak bilenen ve literatüre geçmesini sağlayan uygulama General Electric tarafından yapılmıştır. GE CEO'su Jack Welch tarafından 1999 yılında genç çalışanlar görevlendirilmiş, 500 üst düzey yöneticinin interneti daha aktif bir şekilde kullanabilmesi ve yeni uygulamaları öğrenebilmesi amacıyla bir mentorluk programı düzenlenmiştir. Bu uygulama tersine mentorluk programının resmi olarak ilk kullanımı olarak değerlendirilmektedir (Chaudhuri \& Ghosh, 2012: 56).

Genel olarak tersine mentorlukta mentor mentiden daha genç olmaktadır (Finkelstein, Allen \& Rhoton, 2003). Ancak tersine mentorluk yaşa bağıml olmayan kuşaklararası bir mentorluk türüdür ve her zaman gençten yaşliya doğru olmayabilir (Harvey, McIntyre, Thompson Heames \& Moeller, 2009). Bir internet araştırmasına göre tersine mentorluğun, tarafların hem öğrenebileceği hem de öğretebileceği bir mentorluk ilişkisi olduğu iddia edilmiştir (Starcevich, 2001).

Bir uygulama olarak tersine mentorluğun hedeflerine ulaşabilmesi, fonksiyonlarının doğru bir işlerlik kazanması ve sürecin verimli sonuçlar üretebilmesiyle ilişkilidir. Geleneksel mentorluk, büyük bir çoğunluğu Kram (1985)'ın ortaya koyduğu işlevler ve alt işlevler kapsamında değerlendirilirken (Allen, Eby, Poteet \& Lentz, 2004); tersine mentorluk ilişkisi, geleneksel mentorluk ilişkisiyle ortak olan birçok alt işlevi de içinde barındıran kariyer, psiko-sosyal ve rol model fonksiyonu olarak üç ana işlev bünyesinde şekillenmektedir (Murphy, 2012).

Kariyer işlevi ile bilgi paylaşımı, koçluk, açı̆̆a çıkarma ve görünürlük, yetenek gelişimi, meydan okuma ve zorlu sınavlar ve sosyal ağlar alt işlevleri ifade edilmek istenmektedir. Kisaca ifade edilecek olursa:

- Bilgi paylaşımı: Tersine mentorluğun ana hedeflerinden biri olarak kabul edilmektedir. Mentorun teknoloji, kuşak eğilimleri, çeşitlilik, risk alma ve küresel bakış açısıyla olayları algılama gibi konulardaki uzmanlık bilgilerini paylaşmalarını ifade etmektedir (Harvey 
vd., 2009; Piktialis, 2009). Bununla birlikte tersine mentorluk aynı zamanda karşılıklı bir ilişki olduğundan menti de örgütsel konular, işle ilgili sorumluluklar veya kariyer planlama ve gelișimi gibi birçok konuda kendi yetkinliklerini sunabilir (Kram, 1985).

- Koçluk: Tersine mentorluk sürecine dâhil olan mentinin, özel ve profesyonel yaşamda gelişiminin sağlanmasını hedefleyen ve tümüyle güven ve gizlilik esasına dayanan bir süreçtir (Budak, 2016: 370). $\mathrm{Bu}$ doğrultuda tersine mentorluk amaçlarından biri olan gelişim ve ilerleme koçlukla elde edilebilir.

- Açığa çıkarma ve görünürlük: İlişkinin hem öğreten hem de öğrenen tarafi, örgüt içerisinde düzenli bir iş ilişkisi kurmuş olurlar. Bu ilişki de birbirlerinin kendi iş çevreleri arasında görünürlük ve tanınırlığını sağlayabilmektedirler (McCoy, 2015).

- Yetenek gelişimi: Tersine mentorluk ilişkisinin önemli amaçlarından biri de çeşitli açılardan daha yetenekli mentor ile bu konularda daha az yetenekli olduğu düşünülen menti arasında bir yetenek gelişiminin önünün açılmasıdır (Murphy, 2012).

- Meydan okuma ve zorlu sinavlar: Mentor ve menti kendi jenerasyonlarının temel özelliklerini, tutum ve değerlerini taşıyacaklarından bu ikili arasında bir çatışma çıkma olasılığı bulunmaktadır. Taraflar fikirlerini sunarken, kendine özgü kimliğe sahip olmaları sebebiyle mentorların ve mentilerin birbirlerine meydan okumaları muhtemeldir (Hays \& Swanson, 2011: 3).

- Sosyal ağlar: Mentorun teknolojiyi kullanımındaki rahatlığ oluşturduğu sosyal ortamlar menti için iletişim ağı oluşturmada bir firsat olabilir. Bununla birlikte mentiler için de mentorlarla örgüt içinde hali hazırda çalışmakta olan kıdemli üst seviye çalışanlarla diyalog kurabilmelerinin yolunu açabilir (Murphy, 2012: 559).

Destek ve geribildirim, kabul ve onaylama, arkadaşlık ve cesaretlendirme alt işlevleri ise psikososyal işlevi ifade etmektedir. $\mathrm{Bu}$ alt işlevler aşağıda kısa bir şekilde açıklanmaktadır:
- Destek ve geribildirim: Mentorluk ilişkisinde mentor ile mentinin iyi anlaşabilmesi ve birbirlerini dinlemeleri çok önemlidir. Sorunların çözümü ve karar verme sürecinde mentinin katkısını teşvik etmek, ihtiyaç duyulduğunda ona yardım etmek, bireysel ve profesyonel amaçlarıyla ilgilenmek ve empatik iletişim içinde olmak mentorun sorumluklarından birkaçıdır (Barutçugil, 2004: 361-362).

- Kabul ve onaylama: Bir ilişkide tarafların birbirini kabul edip onaylaması o ilişkinin devamı için oldukça önemli olarak değerlendirilir. Tersine mentorlukta da genç mentor ile olgun menti arasında bir kabul ve onaya ihtiyaç olduğu açıktır. Menti, kendisinden yaşça küçük mentoru kabul ederek mentorla olan ilişkisine önyargısız başlamalıdır (Murphy, 2012).

- Arkadaşlık: Milenyum kuşağı çalışanları için önemli olan motivasyon kaynaklarından biri de arkadaşlıktır (Trunk, 2007). Bu fonksiyon tarafların birbirlerinden hoşnut olması, anlayışlılık, hem işte hem de iş dışında eğlenceli zaman geçirme ile sonuçlanan sosyal etkileşim olarak tanımlanır (Allen 2003: 135).

- Cesaretlendirme: Mentorluk sadece tavsiyeler veren bir süreç olmayıp karşılıklı iletişim, duyarlılık, cesaretlendirme ve gelişim becerilerini de içeren bir süreçtir (Galbraith, 2003: 10).

Tersine mentorluğun üçüncü ve son fonksiyonu olan rol model işlevi; yeni bakış açıları kazandırılması, davranışlara özenme ve ortak değerler belirleme olarak şu şekilde açıklanmaktadır:

- Yeni Bakış Açısı: Tersine mentorluk ilişkisi geleneksel mentorlukta olduğu gibi mentinin gelişimine destek vermek, kendi hayat tecrübelerinden hareketle ak1l vermek, iş hayatı ve birçok genel konuda farklı ve yeni bir bakış açısı kazanılmasını sağlamak amaçlı bir çalışma olarak ifade edilmektedir (Köktürk, 2006).

- Davranışlara Özenme: Mentorun tutumları, değer yargıları ve davranışı mentinin benzemek isteyebileceği bir model oluşturur (Shea 2002: 27). Bilgi kaynaklarını elde etmede ve firsatlar yaratmada yardımcı olan kişiler; kişilik modelleri, davranışları, yaşantısı ve kişiliği ile diğer taraflara rol modeli oluştururlar 
(Zelditch 1990: 1). Tersine mentorlukta da mentorun ve mentinin davranıșları karşı tarafça benimsenip tekrar edilebilir.

- Değerlerle Tanımlama: Gelişmiş güçlü bir ilişki, hem mentor hem de mentinin birbirlerini tanımlayabilmelerini sağlayacak ayrıca gelecek davranışlarını şekillendirmede yararlanacakları pozitif yönleri bulmalarını kolaylaştıracaktır (Murphy, 2012).

Yukarıda temel fonksiyonları açıklanan tersine mentorluk uygulamasının işletmelerce rağbet görmesi ve daha fazla uygulanıyor olması uygulamayı daha görünür hale getirmiștir. $\mathrm{Bu}$ görünürlük sadece literatüre ve çeşitli iş dergilerine değil sinemaya kadar birçok alana uzanmış ve böylece tersine mentorluk ile ilgili çalıșmaların yapılabileceği yeni mecralar elde edilmiștir. $\mathrm{Bu}$ çalışmada da popüler kültür unsurlarından bir sinema filmi araştırmaya dâhil edilmiştir.

\section{POPÜLER KÜLTÜR ve YÖNETIM ÇALIŞMALARI}

Popüler kültür; belli bir gruba ait olmayan, çoğunluk tarafından paylaşılan inançlar, pratikler ve bunların içerdiği normlardır (Oktay, 2004). Halkın kültürü olan popüler kültür, sürekli değişmesi, yapay ve medyatik olmasından dolayı seçkin kültürden ayrılır. Popüler kültürün esas amacı eğlencedir.

Butler'a (1997) göre sosyal araștırmalar sadece fizik, matematik ve mantık gibi bilim alanlarındaki uygulamalar (teknikler) ile açıklanamaz; roman, dizi, film ve opera gibi alanlardan da öğrenilebilir. Benzer şekilde Phillips (1995) yönetim ve organizasyon çalışmalarında fillm, dizi, şiir ve romanların kullanılmasının örgütleri anlamada yeni imkânlar sunduğunu ifade etmiştir. Popüler kültür araçları örgüt ve insan ilişkileri ile ilgili akademik literatürün yüzeyselliğinin aksine detayları işleyerek örgütlerin daha iyi anlaşılmasını sağlayabilir (Rhodes, 2001; Godfrey-Smith, 2009). Örgütlerin popüler kültür gösteriminde cinsiyet, duygular, güç mücadeleleri, mitler, başarı ve başarısızlığın sonuçları gibi yönetim metinlerinde genellikle göz ardı edilen içerikler bulunur (Munro \& Huber, 2012). Bu içerikler "örgütsel yaşamın kalbine girerek" günlük iş süreçlerinin anlaşılmasını sağlayabilir (Hassard \& Holliday, 1998).

$\mathrm{Bu}$ bağlamda popüler kültür ürünleri örgütleri ve insan ilişkilerini anlamak için yönetim yazınında alternatif bir yöntem olarak kullanilabilmektedir (Alakavuklar \& Çakar, 2012: 404). Yabancı yazında; Mad Men (Buzzanell \& D’Enbeau, 2014),
Solaris (Tirado, 1999), Southpark (Rhodes, 2002), Simpsons (Rhodes, 2001), The Office (Tyler \& Cohen, 2008) gibi dizi-film analizleri ile çeşitli roman analizleri (Czarniawska, 2009; Spoelstera, 2009) yapılmıştır. Yerli yazında ise epik filmlerde liderlik (Erkuş, Tabak \& Coşkun, 2007), kadınlar ve direnç (Alakavuklar \& Çakar, 2012), örgüt, edebiyat ve zaman (Yıldırım, 2007), kurumların ortaya çıkması ve meşrulaşmasının Saatleri Ayarlama Enstitüsü adlı roman üzerinden açıklama (Erdemir, 2010; Taşc1 \& Erdemir, 2010; Erdemir \& Koç, 2015), Koro filmi üzerinden durumsal eğitim modelinin sorgulanması (Tofur, 2018a), Die Welle filmi ile örgüt kültürünü oluşturan unsurların incelenmesi (Tofur, 2018b), İKY ve örgütsel davranış alanlarının yansımalarının sinemada arandığı araştırma (Yıldiz, Gündoğmuş, Yener Aydın \& Atalay, 2018) gibi çalışmalar popüler kültür araçlarında yönetim ve insan ilişkilerini inceleyen araştırmalara örnek verilebilir.

\section{ARASTIRMANIN YÖNTEMI ve AMACI}

Bu çalışmada, The Intern (Stajyer) filminde tersine mentorluk konusunun nasıl işlendiğini ve tersine mentorluğun hangi işlevlerine değinildiğini belirlemek amaç olarak belirlenmiştir. Nitel araştırma yönteminin benimsendiği bu çalışmada, analiz tekniği olarak betimsel analiz tekniğinin kullanılması uygun görülmüștür. Betimsel analizde elde edilen veriler, daha önce belirlenen başlıklar (temalar) altında özetlenmekte ve yorumlanmaktadır. $\mathrm{Bu}$ analiz türünde veri kaynaklarından bazı alıntılar yapılarak çalışmanın güvenirliğine katkı yapılabilir. Ayrıca yapılan alıntılar ile çarpıcı görüşler çalışmaya yansıtılmış olur (Altunışık, Coşkun, Bayraktaroğlu \& Yıldırım, 2015: 324).

Araştırmanın amacı doğrultusunda film, araştırmacılar tarafından ayrı ayrı birçok kez izlenmiş, tersine mentorluk açısından önem arz ettiği düşünülen sahnelerin ve diyalogların olduğu dakikalar kaydedilmiştir. Daha sonra filmin altyazısına erișilerek ilgili dakikalarda geçen diyaloglardan bir altyazı dökümü oluşturulmuştur. Tersine mentorluk alt fonksiyonları birer tema olarak belirlendiğinden altyazı dökümü araştırmacılar tarafindan temalara uygun gelecek şekilde kodlanmıştır. Ortaya çıkan kodlamalar arasındaki farklılıklar bir kez daha değerlendirilerek fikir birliğine varılmış ve her bir tema için filmden hareketle ilginç görülen bölümler paylaşılmıştır. 


\subsection{The Intern (Stajyer) Film İçeriği}

Film analizine geçmeden önce Stajyer filmi hakkında kısaca bilgi vermek faydalı olacaktır. Nancy Meyers'ın senaryosunu yazdığı ve çekimleri için kamera arkasına geçtiği The Intern (Stajyer) filmi 2015 yılında gösterime girmiştir. Filmin başrol oyuncuları Anne Hathaway ve Robert De Niro'dur. Film bir şirkette başlatılan stajyerlik uygulaması ve sonrasında yaşananları konu alır. Bu uygulamanın ilginç olan tarafi stajyerlerin gençlerden değil 65 yaş üstü bireylerden oluşmasıdır. Başarılı bir şirketin sahibi olan Jules Ostin (Anne Hathaway), önceleri yaşlı bir stajyerle çalışmak istememektedir. Ancak çalışma arkadaşlarının tavsiyesi üzerine ikna olmuş ve yeni bir staj programı başlatılmıştır.

"Deneyiminize ihtiyaç duyuyoruz." ve "Size bildiklerimizi ögreteceğiz." sloganları ile ilana çıkan programın şartları arasında; örgütsel becerilere sahip olmak ve e-ticarete ilgi duymanın yanında başvuruyu yazılı bir metin yerine video ile göndermek vardır. 70 yaşındaki Ben Whittaker (Robert De Niro) bu ilginç deneysel programa kabul edilen ilk kişi olarak belirlenir.

Ben Whittaker, 70 yaşında ve hayatını bir süredir emekli olarak geçiren biridir. Emekli olmak fikrinin gerçekte zannedildiği gibi her şeyin sonu olmadığını keşfeder. Oyuna geri dönebilmek için bir firsata ihtiyacı olan Ben Whittaker, Jules Ostin'in açtığı ve işlettiği moda içerikli bir alışveriş sitesinde ihtiyar bir stajyer olarak işe başlar. Jules Ostin ise genç, hırslı ve sahibi olduğu işletmeyi büyütmek ve hayatta tutmak için gece gündüz çalışan bir girişimcidir. Şirkette çalışan genç çalışanların ortalama yaşını oldukça yükselten Whittaker ile yanında çalıştığ 1 genç girişimci Ostin arasında süreç içerisinde iş ilişkisi sağlam bir dostluğa dönüşecektir. Filmdeki bu stajyerlik ilişkisi, literatürde geçen ve genç bir mentorla yaşlı bir mentinin ilişkisini ifade eden tersine mentorluk kavramı için önemli bir içerik olarak değerlendirilmiş ve çalışmanın temelini oluşturmuştur.

\subsection{Araştırma Bulguları}

Araştırma kapsamında The Intern (Stajyer) filmi, literatürde bahsedilen tersine mentorluk temaları (fonksiyonlar) üzerinden incelenerek aşağıdaki bulgulara ulaşılmıştır. Filmde geçen diyaloglar her bir alt fonksiyon için incelenmiş, önemli ve dikkat çekici kısımlar ilgili bölümlerde paylaşılmıştır.

\subsubsection{Kariyer Fonksiyonuna İlişkin Bulgular}

Kariyer fonksiyonuna ilişkin ulaşılan bulgular aşağıda sırasıyla ifade edilmiştir.
Bilgi Paylaşımı: Mentorun teknoloji, kuşak eğilimleri, risk alma ve geniş bakış açısıyla olayları algılama gibi konularda uzmanlığını paylaşmasını ifade etmektedir. Filmde genç iş arkadaşının Ben'e MacBook kullanımı hakkında yol göstermesi, Facebook hesabı oluşturmada yardımcı olması, yeni iş yapış modelleri ve yeni nesil tüketiciler hakkında bilgi paylaşımında bulunması tersine mentorluk uygulamaları olarak değerlendirilebilir.

Jules Ostin: "Günün sonunda elinde bir bardak şarap ve dizüstü bilgisayarl olan her kadının alışveriş yapma potansiyeli olduğunu biliyorum o kadar. Ve ona klyafetlerin gerçekten üzerine uyacağı sözünü verirsen..." ifadesi Jules'un yeni nesil tüketiciler hakkında sahip olduğu bilgiyi Ben ile paylaşmasına örnek verilebilir.

Koçluk: Filmde bir mentor olarak Jules Ostin'in, Ben Whittaker'a koçluk ettiği herhangi bir alan olduğuna yönelik bir imaya rastlanmamıştır. Koçluğun hem özel hem de iş hayatında bir konu hakkındaki gelişimi ifade ettiği düşünüldüğünde beklenilenin aksine Ben'in hem şirkete yeni bir CEO atanması konusunda hem de evliliğindeki sorunların düzeltilmesi hakkında Jules'e koçluk ettiği düşünülebilir.

Açığa Çıkarma ve Görünürlük: Her iki tarafta örgüt içerisinde düzenli iş ilişkisi kurduğundan birbirlerinin yaşıtları arasında görünürlük ve tanınırlık artmaktadır. Nitekim filmde Ben kısa sürede şirketteki herkes tarafından bilinmekte ve sevilmektedir.

Cameron: "Herkesin sevdiği bir adam var. Harika görünüyor."

Davis: "Birinci sınıfta işler nasıl gidiyor?"

Ben Whittaker: "Burada herkesin amcasıymışım gibi hissetmeye başladım yeminle."

Yapılan bir görevlendirme sonrasında Ben Whittaker, Jules Ostin'in yönetici asistanı olan Becky'ye yardımcı olmaya başlar. Becky'den bir işle ilgili raporların kendisine gönderilmesini isteyen Jules, aynı raporların Ben'e de gönderilmesini ister. Hatta daha önce Becky'den hiç istemediği şekilde raporlara önce Ben'in bakmasını ister. $\mathrm{Bu}$ sayede daha fazla sorumluluk ve görev vererek ofiste Ben'e daha fazla yer açar. Aşağıda konu ile ilgili diyalog bulunmaktadır:

Jules: “Teşekkürler. Müşteri satın alma verisinin üzerinden geçmek istiyorum. Ben ona da bir göz atsin. Aslında önce bir Ben göz atsın."

Becky: "Tamam."

Jules: "Endişelenme Becky. Bir desteğin olması iyidir." 
Yetenek Gelişimi: Stajyerlerin hangi birimlerde çalışacağı yetenek yönetimi birimi tarafından belirlenmiş, diğer stajyerler pazarlama, fotoğraf stüdyosu gibi birimlerde görevlendirilmiş olmasına rağmen; Ben şirketin kurucusu olan Jules Ostin'in yanına verilmiştir. Filmde Ben'in herhangi bir yeteneğinin doğrudan geliştiğini gözlemlemek oldukça güç olsa da Ben'in bilgisayarı etkin kullanmaya başlaması, Facebook gibi sosyal medya mecralarına giriş yapmaya çalışması, yeni kuşaktan bireylerle aynı ortamda çalışarak diyaloga girmesi kısmen de olsa birer gelişim olarak düşünülebilir.

Meydan Okuma ve Zorlu Sinavlar: Mentor ve menti ikilisinin birbirlerini tanımak ve birbirlerinin sınırlarını anlamak üzere girdikleri çeşitli mücadeleleri ifade eder. Filmde stajyerlerin görevlendirilmelerinin yapılmasının ardından Jules ilk tanışmada Ben'in başka birimde çalışmasını ve bu durumun onun için daha iyi olacağını ifade etmesine rağmen Ben başka birime geçmek istemez ve meydan okur.

Jules Ostin'in "Sana yaptıracak pek ișim yok benim. Bana sorarsan, üretim veya pazarlama departmanında çok daha iyi olursun. Oralar biraz daha sakin, yetişmen kolay olacaktır. Daha mutlu olacaksın inan bana. Çalıșması zevkli biri değilim ben." demesi üzerine Ben Whittaker "Milletten ögrendiğim de o yönde ama ben herkesle iyi anlaşabilirim ve buraya senin dünyay ögrenmeye ve elimden geldiğince yardım etmeye geldim. Başka birime geçmek istemiyorum" şeklindeki sözleri tarafların birbirine meydan okuduğunu göstermektedir.

Sosyal Ağlar: Mentorun teknolojiyi kullanmadaki rahatlığ 1 ve online olarak oluşturduğu network menti için bir iletişim ağı oluşturmada fursat olabilir. Ayrıca menti, mentor aracılığıyla örgütteki diğer kıdemli çalışanlar ile ilişki kurabilir. Ben şirkette Facebook'a kayıt olmaya çalışırken Jules Beni görür ve profilli oluşturmada yardım eder. İlk arkadaş olarak da kendisini ekleyerek network oluşturmasının ilk adımlarını atar:

Jules: "Şimdi neye ihtiyacın var biliyor musun? Arkadaşın olacak birisine"

Ben: "Diğer stajyerlerle arkadaş olurum. Sabaha nasıl yapılacağını gösterirler bana."

Jules: "Beni arkadaş olarak ekleyebilirsin."

Ben: "Peki teșekkürler."

Jules: "Ne demek. Tamamdır. Tebrikler artık resmi olarak Facebook neslinin bir parçasısın."

Ben: "Harika."

Burada mentor mentiye sosyal ağ platformu olarak Facebook profili oluştururken aynı zamanda mentinin kişisel özelliklerini de öğrenmekte ve samimi bir iletişimin temellerini atmaktadır. Ayrıca arkadaş sayısının artması için ilk olarak mentor kendini eklemekte böylece diğer çalışanların eklemesini cesaretlendirmektedir.

\subsubsection{Psiko-sosyal Fonksiyon Fonksiyona İlişkin Bulgular}

Aşağıda psiko-sosyal fonksiyona ilişkin çeşitli bulgular sunulmuştur.

Destek ve Geribildirim: Filmdeki stajyerlik ilişskisi incelendiğinde tersine mentorluğun bir alt fonksiyonu olan destek ve geribildirimin varlığına yönelik herhangi bir bulguya rastlanmamıştır.

Kabul ve Onaylama: Menti (Ben) mentorun (Jules) bilgi ve becerilerine güvenmekte ve kendini ona emanet etmektedir.

Ben Whittaker: "Bu şirketi tek başına bir buçuk yıl önce sen kurdun ve şimdi 220 çalışanın var. Bunu kimin yaptığını unutma" cümlesi mentorun menti tarafından kabul edildiğini göstermektedir.

Arkadaşlık: Mentor ile mentinin arkadaşlık ilişkisine girebilmesi durumudur. Filmde Ben ve Jules birlikte uzun süre vakit geçirmekte ve profesyonel iş ilişkisi arkadaşlık ilişkisine doğru kaymaktadır. Özel hayatlarından bahsetmeleri arkadaşl1k ilişkisinin kurulduğunu göstermektedir:

Jules Ostin: "İ̧sten falan konuşmak zorunda değiliz. Evlilik? Bana eşinden bahseder misin?"

Ben Whittaker: "Adl Molly'di. Ortaokul müdürüydü. Herkes tarafindan sevilirdi. Hani insanların beraber yaşlanmak istediklerini söylediğini duyarsin ya. Biz yaptık onu. 42 yıl sürdü evliliğimiz."

Bunun yanında birlikte barda zaman geçirmeleri, aile ve evlilik üzerine sohbet etmeleri, iş seyahatinde otel odasında TV izlemeleri arkadaşlık ilișkisinin kurulduğunu göstermektedir. Şirketin ve Jules Ostin'in geleceği hakkında filmin sonralarına doğru yaptıkları görüşmeyi ise birbirlerinin arkadaşı olduklarını ifade etmeleriyle sonlandırmışlardır:

Jules: "Bir de sen benim..."

Ben: "Stajyerinim."

Jules: "Ben stajyer/en iyi arkadaş diyecektim."

Cesaretlendirme: Mentor, mentinin üstlendiği veya üstleneceği bir işte onu motive ederek başarılı olması için cesaretlendirir. Bir rapor hazırlaması üzerine görevini tamamlayan Ben, raporu hakkında konuşmak üzere mentorunun yanına gider:

Ben Whittaker: "Merhaba. Satın alma düzenine bir baktım. Daha sonra mı geleyim?" 
Jules Ostin: "Yok yok, içeriye gel. Bayağı hızlı oldu."

Ben Whittaker: "Becky'nin yardımını aldım. Görünüşe göre en fazla reklam yaptığın yer müşterilerine en az satış yaptı̆̆ın yer. Ve en az yatırım yaptı̆̆ın kanallar şu anda en az değer görmüş ama en fazla satış potansiyeli olan yerlere önemli ölçüde değer katıyor. Şimdiye kadar buna kanaat getirdim."

Jules Ostin: "Ben, benim için bunun icabına bakabilir misin? Vaktin varsa daha iyi bir plan ile bana gelebilir misin?"

Ben Whittaker: "Memnuniyetle."

Jules Ostin: (Odadaki diğer çalışanlara dönerek) Adam bu işe 40 yılını harcadı.

\subsubsection{Rol Model Fonksiyonuna İlişkin Bulgular}

Tersine mentorluğun önemli bir fonksiyonu olan rol model fonksiyonu ve onun alt fonksiyonları olan yeni bakış açısı, davranışlara özenme ve değerlerle tanımayı ayrı ayrı analiz edebilecek kadar veri elde edilememesi sebebiyle rol modellik teması bir bütün olarak incelenmiştir.

Rol Model: Rol model fonksiyonu mentorun arzu verici bir örnek oluşturmasını ve mentinin bununla özdeşleşmesini içerir. Filmde yaşça büyük olan Ben (menti) Jules'a hayran olmakta ve onun çalışma aşkını ve yaratıcılığını örnek almaktadır. Bu fikrini açıkça mentora söylemektedir. Facebook profili oluştururken ilham aldığın kişiler sorusuna "Jules Ostin" demesi. Sonrasinda ise Ben'in "Dalkavukluk yapmaya çalışmıyorum ama uzun zamandır bu işlerdeyim ve senin gibi birisine hiç denk gelmedim. Ilham veriyorsun Jules." demesi ona duyduğu hayranlığının göstergesidir. Başka bir sahnede ise "Senden daha tecrübeli birisi gelebilir ama senin bildiklerini asla bilemeyecekler. Hayatımda hiç böyle bir şeye sahip olamadım ben. Pek fazla insan olamaz yaptı̆̆ın büyük, güzel, heyecan verici şeye. Bir rüya gibi, değil mi?" şeklindeki ifadesi mentorunu rol model olarak benimsediğini göstermektedir.

Tersine mentorluk çalışmalarında kavramın içeriğini, fonksiyonlarını ve sınırlarını belirleyen Murphy (2012)'nin yaklaşımının benimsendiği çalışmada, filmin kahramanları olan Ben ile Jules arasındaki ilişki incelenmiştir. Bahse konu olan iş ilişkisinde kariyer fonksiyonu alt işlevlerinden bilgi paylaşımı, açığa çıkarma ve görünürlük, meydan okuma ve zorluklar, sosyal ağlar; psiko-sosyal fonksiyonu alt işlevlerinden kabul ve onaylama, arkadaşlık, cesaretlendirme ve rol model fonksiyonu işlevlerine ilişkin bulgulara erişilmiştir. Koçluk ve yetenek gelişimi ile destek ve geribildirim işlevlerinin ise filmde işlenmediği ortaya çıkarılmıştır.

\section{SONUC ve DEĞERLENDIRME}

Geleneksel mentorluğun aksine genç ve kıdem olarak daha az çalışma süresine sahip birisinin yaş ve kıdemi fazla olan birisine teknoloji ve kuşak farklılığı başta olmak üzere bazı konularda bilgi ve uzmanlığını paylaşması durumu olan tersine mentorluk, iş dünyasında uygulanan ve oldukça popüler olan bir kavramdır. Son yıllarda tersine mentorluk ile ilgili akademik çalışmalarda da artan bir ilgi söz konusudur.

$\mathrm{Bu}$ çalışmada tersine mentorluk konusu The Intern (Stajyer) adlı film üzerinden araştırılmış ve tersine mentorluk fonksiyonlarının filmde nasıl işlendiği analiz edilmiştir. Tersine mentorluk konusunun bir filmde işlenmesi, kavramın ve özellikle Murphy (2012) tarafından ortaya konan fonksiyonların önemli bir kısmının daha net bir biçimde gösteriliyor olmasını ve konunun daha iyi anlaşılabilmesini sağlamıştır. $\mathrm{Bu}$ tarz bir filmin varlığından haberdar olunmasını sağlamak ve hangi fonksiyonların işlendiğini tespit etmedeki amaçlardan biri düzenlenen eğitimlerde eğitimcilere materyal sağlanması ve bu film üzerinden tersine mentorluk kavramının tartışılabileceğini göstermektir.

$\mathrm{Bu}$ araştırmadaki bir diğer amaç ise nitel yöntem kullanılarak anket gibi nicel tekniklerin gözden kaçırabildiği hususları ortaya daha net koymaktır. Bir kavramın hem somut hem de soyut taraflarının daha iyi özümsenebilmesi için film, belgesel, resim, röportaj, kitap gibi eserlerin varlığı bir firsat olarak değerlendirilebilir. $\mathrm{Bu}$ çalışma ile bu amaçlara ulaşıldığı düşünülmektedir.

Yabancı yazında sıkça kullanılan ve araştırmalara konu edilen film, dizi, roman gibi kültürel unsurlar yerli yazında da daha fazla tercih edilebilir. Çeşitli araçlar üzerinden konu/kavram açıklama tarzı ile oluşturulan yayınlar yerli yazında da bir kavramın, olayın veya olgunun daha iyi anlaşılabilmesi ve aktarılabilmesi için uygun birer seçenek olarak değerlendirilebilir. Gelecek çalışmalarda, mevcut tersine mentorluk fonksiyonlarını tespit etmenin ötesinde iş dünyasının aktörleri (yönetici ve çalışanlar) ile derinlemesine mülakat yapılarak yeni boyutlar ortaya konabilir.

\section{ETIKK BEYANATI}

Destek Bilgisi: Bu çalışma, kamu, ticari veya kar amac1 gütmeyen kuruluşlar gibi herhangi bir organizasyondan destek almamıştır.

Çıkar Çatışması: Tüm yazarlar adına, sorumlu yazar çıkar çatışması olmadığını belirtir. 
Etik Onay: Çalışma, insan katılımcıları içermediğiden etik onay gerekmemektedir.

Bilgilendirilmiş Onam Formu: Çalışma, insan katılımeı içermediğinden bu forma ihtiyaç duyulmamıştır.

\section{KAYNAKÇA}

Alakavuklar, N. \& Çakar, U. (2012). Örgütsel Açıdan Cinsiyet, Kadınlar ve Yönetsel Kontrole Direnç. 20. Yönetim ve Organizasyon Kongresi, 24-26 Mayıs, Dokuz Eylül Üniversitesi, İzmir.

Allen, T. D. (2003). Mentoring others: A Dispositional and Motivational Approach. Journal of Vocational Behavior, 62(1), 134-154.

Allen, T. D., Eby, L. T., Poteet, M. L., Lentz, E. \& Lima, L. (2004). Career Benefits Associated with Mentoring for Protégés: A Meta-Analysis. Journal of Applied Psychology, 89(1), 127.

Altunışık, R., Coşkun, R., Bayraktaroğlu, S. \& Yildirim, E. (2007). Sosyal Bilimlerde Araștırma Yöntemleri. Sakarya: Sakarya Yayıncılı.

Barker, E. R. (2006). Mentoring- A Complex Relationship. Journal of the American Academy of Nurse Practicioners, 18, 56-61.

Barutçugil, İ. (2004). Stratejik Insan Kaynakları Yönetimi. İstanbul: Kariyer Yayınları.

Budak, G. (2016). Yetkinliğe Dayal Insan Kaynaklart Yönetimi. Ankara: Nobel Akademik Yayıncılık.

Busen, N. H. \& Engebretson, J. (1999). Mentoring in Advanced Practice Nursing: The Use of Metaphor in Concept Exploration. The Internet Journal of Advanced Nursing Practice, 2(2), 10.

Butler, R. (1997). Stories and Experiments in Social Inquiry. Organization Studies, 18(6), 927-948.

Buzzanell, P. M. \& D'Enbeau, S. (2014). Intimate, Ambivalent and Erotic Mentoring: Popular Culture and Mentor-Mentee Relational Processes in Mad Men. Human Relations, 67(6), 695-714.

Chaudhuri, S. \& Ghosh, R. (2012). Reverse Mentoring: A Social Exchange Tool for Keeping The Boomers Engaged and Millennials Committed. Human Resource Development Review, 11(1), 55-76.

Crisp, G. \& Cruz, I. (2009). Mentoring College Students: A Critical Review of the Literature Between 1990 and 2007. Research in Higher Education, 50.5, 525-545.

Czarniawska, B. (2009). Distant Reading: Anthropology of Organizations Through Reading Novels. Journal of Organizational Change Management, 22(4) 357-372.

Çınar, Z. (2010). Coaching ve Mentoring. Paradoks Ekonomi. Sosyoloji ve Politika Dergisi 1.1, 1-25. $\mathrm{http} / /$ www.makaleler.com/insan-kaynaklarimakaleleri/coaching-ve-mentoring.htm Erişim Tarihi: 06.03.2017. 
Erdemir, E. \& Koç, U. (2015) "Legitimacy Work in the Emergence of New Organizational Forms: The Case of Tanpinar's The Time Regulation Institute", 110th Annual Meeting of American Sociological Society, 22-25 Ağustos, Chicago, ABD.

Erdemir, E. (2010). Kurumların Ortaya Çıkışında Meşrulaştırma Stratejilerinin Kullanımı: Saatleri Ayarlama Enstitüsü Örneği. 18. Ulusal Yönetim ve Organizasyon Kongresi, 20-22 Mayıs, Çukurova Üniversitesi, Adana, 299-306.

Erkuş, A., Tabak, A. \& Çoşkun, E. (2007). Liderlik 7'nci Sanattan Ögrenilebilir mi? Epik Filmlerden Liderlik Analizleri. 15. Ulusal Yönetim ve Organizasyon Kongresi, 25-27 Mayıs, Sakarya Üniversitesi, Sakarya, 34-43.

Finkelstein, L. M., Allen, T. D. \& Rhoton, L. A. (2003). An Examination of the Role of Age in Mentoring Relationships. Group \& Organization Management, 28(2), 249-281.

Galbraith, M. W. (2003). Celebrating Mentoring. Adult Learning, 14(1), 2-3.

Godfrey-Smith, P. (2009). Theory and Reality: An Introduction to the Philosophy of Science. Chicago: University of Chicago Press.

Harvey, M., McIntyre, N., Thompson Heames, J. \& Moeller, M. (2009). Mentoring Global Female Managers in the Global Marketplace: Traditional, Reverse, and Reciprocal Mentoring. The International Journal of Human Resource Management, 20(6), 1344-1361.

Hassard J. \& Holliday, J. (eds) (1998) OrganizationRepresentation: Work and Organization in Popular Culture. London: SAGE.

Hayes, E. F. (2005). Aproaches to Mentoring: How to Mentor and Be Mentored. Journal of The American Academy of Nurse Practitioners, 17(11), 442-445.

Hays, B. A. \& Swanson, D. J. (2012). Public Relations Practitioners' Use of Reverse Mentoring in the Development of Powerful Professional Relationships. PRism: Exploring Power and Public Relations, 9(2).

Köktürk, M. (2006). Yaşanmış Hikâyelerle Koçluk Mentorluk. İstanbul: Morpa Kültür Yayınları.

Kram, K. E. (1985). Mentoring at Work: Developmental Relationships in Organizational Life. Administrative Science Quarterly. 30.3, 454-456.

McCoy, R. C. (2015). Ethical Diversity in Strategic Communications: The Hiring, Training, and Mentoring of Millennial Minorities (Yayımlanmamış Doktora Tezi), West Virginia University, ABD.
Munro, I. \& Huber, C. (2012). Kafka's Mythology: Organization, Bureaucracy and the Limits of Sensemaking. Human Relations, 65(4), 523-543.

Murphy, W. M. (2012). Reverse Mentoring at Work: Fostering Cross-Generational Learning and Developing Millennial Leaders. Human Resource Management, 51(4), 549-573.

Oktay, A. (2004). Sanat ve Siyaset. İstanbul: Everest Yayınlar1.

Phillips, N. (1995). Telling Organizational Tales: On The Role of Narrative Fiction in The Study of Organizations. Organization Studies, 16(4), 625-649.

Piktialis, D. (2009). How "Reverse Mentoring" Can Make Your Organization More Effective. Encore Careers, January, 26.

Rhodes, C. (2001). The Simpsons, Popular Culture, and the Organizational Carnival. Journal of Management Inquiry, 10(4) 374-383.

Rhodes, C. (2002). Coffee and the Business of the Pleasure: The Case of Harbucks vs. Mr. Tweek. Culture And Organization, 8(4) 293-306.

Shea, G. F. (2002). How to Develop Successful Mentor Behaviors. 3rd Edition. California: Crisp Publications.

Spoelstera, S. (2009). Organizational Brilliance: On Blinding Visions in Organizations. Journal of Organizational Change Management, 22(4) 373-385.

Starcevich, M. M. (2001). What is Unique About Reverse Mentoring, Survey Results. Retrieved March, 16, 2002.

Stone, F. M. (2002). Coaching and Mentoring. Chichester: John Wiley \& Sons.

Taşc1, D. \& Erdemir, E. (2010). Kurumlar Nasıl Ortaya Çıkar? Yeni Kurumsal Kuram Perspektifinden Bir Sosyal Inşâ Süreci Olarak Saatleri Ayarlama Enstitüsü. 1. Örgüt Kuramı Çalıştayı, 12-13 Şubat, Başkent Üniversitesi, Ankara, 129-152.

Tirado, F. J., Alcaraz, J. M. \& Domenech, M. (1999). A Change of Episteme for Organizations: A Lesson From Solaris. Organization 6(4), 673-690.

Tofur, S. (2018)a. Sinematografik Anlatıda HerseyBlanchard Durumsal Liderlik Modelinin Eğitimde Kullanılabilirliği: Koro Filmi. Kuramsal Eğitimbilim Dergisi, 11(4), 822-837.

Tofur, S. (2018)b. Örgüt Kültürünü Oluşturan Unsurlar:" Die Welle (Tehlikeli Oyun)" Filmi Analizi. Electronic Turkish Studies, 13(19).

Trunk, P. (2007). What Gen Y Really Wants. Time Magazine, 5. 
Tyler, M. \& Cohen, L. (2008). Management in/as Comic Relief: Queer Theory And Gender Performativity in The Office. Gender, Work \& Organization, 15(2), 113-132.

Y1ldırım, E. (2007). Zaman, Örgüt ve Edebiyat: Ahmet Hamdi Tanpınar'in Saatleri Ayarlama Enstitüsü Üzerine Bir İnceleme. 15. Yönetim ve Organizasyon Kongresi, Sakarya Üniversitesi, Sakarya.

Yıldız, F. Z., Gündoğmuş, E., Yener Aydın, B. \& Atalay, E. (2018). Insan Kaynaklarl Yönetimi ve Örgütsel Davranışın Sinemaya Yansimaları: Örnek Olay Çalışması. 6. Örgütsel Davranış Kongresi, 2-3 Kasım, Süleyman Demirel Üniversitesi, Isparta, 864-877.

Zelditch, M.(1990). Mentor Roles. Proceedings Of The 32nd Annual Meeting of the Western Association of Graduate Schools, Tempe, Arizona. 